\title{
Patients with n-hexane induced polyneuropathy: a clinical follow up
}

\author{
Y C Chang
}

\begin{abstract}
The prognosis of hexacarbon induced polyneuropathy is usually good, though its clinical course after the cessation of exposure has not been described in detail. Eleven patients with moderate to severe $n$-hexane induced polyneuropathy due to occupational exposure were regularly followed up for a period of four years at the neurological department of the National Taiwan University Hospital. Sensorimotor neuropathy was diagnosed in nine patients and motor neuropathy in two. All were removed from further exposure to n-hexane after aetiological confirmation, but motor disturbance continued to worsen in five cases. Sensory functions were regained earlier than motor functions. All the patients, including one who was tetraplegic and confined to a wheelchair in the early stages, regained their full motor capabilities within one to four years. Three patients with severe neuropathy had residual muscle atrophy in the intrinsic foot and hand muscles. Signs of damage to the central nervous system, including increased tendon reflexes in two patients and leg tightness in six patients, emerged as muscle power was nearing complete recovery. The tightness of the legs gradually disappeared, but muscle cramps of the calves developed and these were still present at the end of follow up. Two patients had mild abnormal colour vision, and the abnormality was still detectable four years later. It is concluded that n-hexane induced neuropathy has a good prognosis, and that spasticity due to damage to the central nervous system is functionally reversible; muscle cramps and dyschromatopsia persist much longer.
\end{abstract}

Chronic hexacarbon intoxication in experimental animals results in symmetrical, distal degeneration of

Department of Neurology, National Taiwan University Hospital, Taipei, Taiwan

Y C Chang
Chronic hexacarbon intoxication in experimental animals results in symmetrical, distal degeneration of axons in the peripheral nervous system (PNS) and in some long tracts of the central nervous system (CNS) ${ }^{1-4}$ In man symmetrical sensorimotor polyneuropathy implicating the PNS is the principal manifestation in subacute or chronic hexacarbon poisoning ${ }^{4-9}$; unequivocal clinical evidence implicating the CNS is usually absent in patients with hexacarbon induced neuropathy. Lower extremity hyperreflexia and spasticity that indicate lesions in the CNS have occasionally been observed on recovery from PNS dysfunction, however, in severely affected victims. ${ }^{2310}$ Schaumburg and Spencer postulated that dysfunction of peripheral nerves masks signs of CNS damage, and these signs may emerge only after the nearly complete regeneration of the peripheral nerves. ${ }^{2}$

From December 1983 to February 198528 printing workers in the Taipei area developed clinically overt $\mathrm{n}$-hexane induced neuropathy as a result of occupational intoxication. Epidemiological, neurographic, and evoked potential findings from that outbreak have been reported elsewhere. ${ }^{11-13}$ Thereafter, both the CNS and PNS manifestations were regularly followed up for four years in 11 of the 28 patients. Special attention was given to the "delayed worsening" of symptoms after cessation of exposure. In the present paper changes in the clinical manifestations on recovery are reported and analysed.

\section{Materials and methods \\ PATIENTS}

Seventeen of the 28 patients with $n$-hexane induced polyneuropathy had returned to south Taiwan and were lost to contact. The remaining 11 (men, ages 1835 at first examination) were followed up neurologically at the National Taiwan University Hospital; monthly for the first two years; bimonthly in the third year; and once every three months in the fourth year. Eight left the printing industry, recuperated at home for several months, and then began working at jobs which did not require contact with organic solvents. The three others returned to the printing factory where $n$-hexane was no longer used and the ventilation system had been improved. 
Table 1 Initial neurological manifestations in 11 patients with n-hexane induced polyneuropathy

\begin{tabular}{ll}
\hline & $\begin{array}{l}\text { No of } \\
\text { patients }\end{array}$ \\
\hline PNS manifestations: & 7 \\
Weakness in legs only & 4 \\
Weakness in arms and legs & 5 \\
Sensory dysfunction in legs only & 4 \\
Sensory dysfunction in arms and legs & 11 \\
Hyporeflexia or absence of tendon reflex & 0 \\
CNS manifestations: & 0 \\
Headache and/or dizziness & 0 \\
Mental change & 0 \\
Sleep disorder & 2 \\
Spasticity or hyperreflexia & 2 \\
Dyschromatopsia (colour plate screening test) & \\
\hline
\end{tabular}

NEUROLOGICAL CHECK UP AND CLINICAL GRADING Neurological examination, inquiry about and inventory of symptoms, and clinical grading were made at each visit. Polyneuropathy was classified into the following grades: grade 5, unable to stand without support or confined to a wheelchair; grade 4, able to stand without support but unable to walk; grade 3, able to walk with support; grade 2, able to walk without support but unable to walk on heels for at least 10 steps; grade 1, able to walk freely on heels but unable to run; and grade 0 , able to run.

\section{NERVE CONDUCTION STUDIES}

At the first visit neurographic studies were carried out on each patient using a Medelec MS6 or Mystro 20 electromyograph. Studies of motor nerve conduction were made on the median, ulnar, peroneal, and tibial nerves using conventional techniques. Sensory conduction velocities were measured for the right median, ulnar, and sural nerves. When the polyneuropathic manifestations improved to a new clinical grade, the neurographic studies were repeated.

\section{Results}

Table 1 shows the initial neurological manifestations present in the 11 patients. Walking difficulty due to

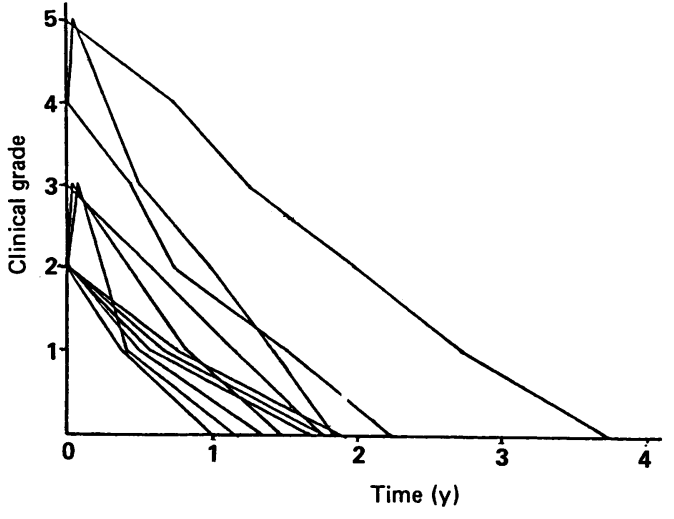

Figure 1 Clinical course of recovery in 11 patients with n-hexane induced polyneuropathy. Delayed worsening that developed before first neurological examination (two patients) is not shown.

weakness of both legs was the main clinical sign. $\mathrm{A} \cong$ detailed inquiry into the patients' histories, however, showed that preceding paresthaesia and numbness with a glove stocking distribution were present in nine patients. Sensory examination disclosed a mild to moderate decrease in vibration, pain, and temperature sensations. Tendon reflexes were obviously decreased and the ankle jerk was absent in all patients. Sphincter functions were intact. None of the patients complained of headache, dizziness, or sleep disorder. Spasticity, increased tendon reflexes, and Babinski's sign were not found. Examinations of the patients' mental states disclosed nothing abnormal. Two patients had mild impairment of colour discrimination (colour plate screening test). Grade 5 polyneuropathy was found in one, grade 4 in two, grade 3 in 11, and grade 2 in seven patients (table 2 ).

\section{CLINICAL COURSE OF PNS MANIFESTATIONS}

Figure 1 shows the course of clinical improvement in the 11 patients. All except the one most severely affected returned to normal daily activities, including running, within 12 to 30 months. The sensory disturbance in patients with sensorimotor poly-

Table 2 Neurological manifestations emerging on recovery or persisting at the end of the four year follow up

\begin{tabular}{|c|c|c|c|c|c|c|c|c|c|c|c|c|}
\hline & \multicolumn{11}{|c|}{ Case } & \multirow{2}{*}{$\begin{array}{l}\text { Total No } \\
\text { of cases }\end{array}$} \\
\hline & 1 & 2 & 3 & 4 & 5 & 6 & 7 & 8 & 9 & 10 & 11 & \\
\hline $\begin{array}{l}\text { Initial neurological grading } \\
\text { PNS manifestations: }\end{array}$ & 5 & 4 & 4 & 3 & 2 & 2 & 2 & 2 & 2 & 2 & 2 & \\
\hline $\begin{array}{l}\text { Delayed worsening of motor function } \\
\text { Delations: }\end{array}$ & \multicolumn{12}{|c|}{ PNS manifestations: } \\
\hline Delayed worsening of sensory function & $\stackrel{t}{-}$ & $\begin{array}{l}+ \\
-\end{array}$ & $\begin{array}{l}+ \\
-\end{array}$ & $\begin{array}{l}- \\
-\end{array}$ & - & - & - & - & + & + & - & 5 \\
\hline Residual muscle atrophy & + & + & + & - & - & - & - & - & - & - & $\overline{-}$ & $\begin{array}{l}0 \\
3\end{array}$ \\
\hline \multicolumn{13}{|l|}{ CNS manifestations: } \\
\hline Hyperreflexia & + & + & - & - & - & - & - & - & - & - & - & 2 \\
\hline Extensor plantar response & - & - & - & - & - & - & - & - & - & - & - & 0 \\
\hline Tightness of legs & + & + & + & + & - & + & - & + & - & - & - & 6 \\
\hline Muscle cramps. & + & + & + & + & - & + & - & + & - & - & - & 6 \\
\hline Dyschromatopsia & - & - & - & - & - & + & - & - & - & + & - & 2 \\
\hline Delayed worsening of neurographic findings & + & - & + & - & + & + & + & + & + & + & + & 9 \\
\hline
\end{tabular}




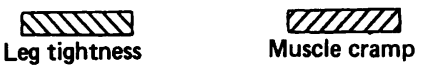

Case 8 काप

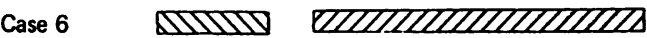

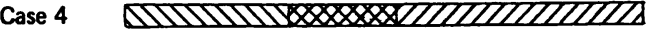

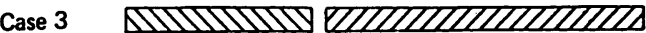

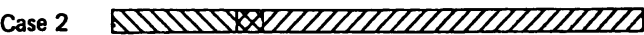

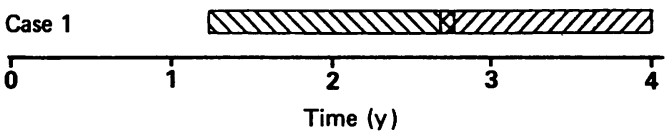

Figure 2 Chronological relation between leg tightness and muscle cramps in six patients with $n$-hexane induced polyneuropathy.

neuropathy disappeared much sooner than the motor disorders, usually within three or four months. The most severely afflicted patient regained the capability to run, although awkwardly, nearly four years later, but his sensory functions had returned to normal within 18 months.

Five patients, mainly those with severe neuropathy, complained of deterioration of motor function after exposure to $\mathrm{n}$-hexane had ceased. This deterioration lasted for two to three months. In contrast, sensory problems did not show delayed worsening in any of the patients (table 2). Atrophy of the intrinsic hand and foot muscles, was found-as a sequela of $\mathrm{n}$-hexane induced neuropathy in three patients who had grade 4 or grade 5 polyneuropathy. Daily manual and running activities were not disturbed. Pronounced atrophy of the foot muscles in the most severely afflicted patient resulted in a pes cavus deformity.

\section{MANIFESTATIONS OF CNS DAMAGE}

A gradual return of deep tendon reflexes to normal was the rule with ankle jerks reappearing last.
Tendon reflexes became hyperactive in two patients with severe neuropathy about 18 months after onset. Hyperreflexia in these two patients was mild and seen only in the legs. Neither ankle clonus nor extensor plantar response was found throughout the whole course.

Tightness of the legs was a complaint of six patients, mainly in those with severe neuropathy. They usually described tightness of the hamstrings in the morning, which lessened to some extent after walking or exercise. No obvious spastic gait was found during the follow up neurological examinations. Leg tightness commonly developed eight to 15 months after onset of neuropathy and gradually diminished six to 20 months later (fig 2).

\section{MUSCLE CRAMPS}

Muscle cramps in the legs, especially in the calves, were reported by those patients with leg tightness. Cramps occurred almost exclusively in the early morning just after waking. When their motor activity improved to grade 1, tightness of the legs gradually lessened, but muscle cramps became more unpleasant. This symptom was still present at the last visit four years after onset of neuropathy (fig 2). Muscle cramps in the most severely afflicted victim also occurred after exercise and involved both feet and hands.

\section{ELECTRONEUROGRAPHIC FINDINGS}

Table 3 lists the initial neurographic findings from the right limbs. A pronounced decrease in nerve conduction velocities (NCVs), profound amplitude reduction of muscle action potentials (MAPs) and sensory action potentials (SAPs), and obvious prolongation of distal latencies were characteristic.

On serial neurographic follow up, a further decrease in the amplitude of MAPs in at least one nerve was found in six patients, mainly in the peroneal nerve. Five patients had further slowing of motor NCVs, but distal latencies improved. In sensory conduction studies a further reduction of SAP amplitude was seen in five patients. Delayed

Table 3 Mean initial neurographic findings in 11 patients with n-hexane induced polyneuropathy (laboratory norms in parentheses)

\begin{tabular}{|c|c|c|c|c|c|c|}
\hline & $\begin{array}{l}C M A P(m V) \\
\text { or } S A P(\mu V)\end{array}$ & $(S D)$ & $\begin{array}{l}\text { Distal } \\
\text { latency (ms) }\end{array}$ & $(S D)$ & $\begin{array}{l}N C V \\
\left(m s^{-1}\right)\end{array}$ & $(S D)$ \\
\hline $\begin{array}{l}\text { Motor conduction: } \\
\text { Median nerve } \\
\text { Ulnar nerve } \\
\text { Peroneal nerve } \\
\text { Tibial nerve }\end{array}$ & $\begin{array}{l}4 \cdot 1(8 \cdot 9) \\
4 \cdot 2(7 \cdot 8) \\
1 \cdot 8(5 \cdot 9) \\
4 \cdot 0(10 \cdot 2)\end{array}$ & $\begin{array}{l}2 \cdot 1(3 \cdot 0) \\
1.7(2 \cdot 2) \\
1 \cdot 0(1 \cdot 9) \\
2 \cdot 4(3 \cdot 7)\end{array}$ & $\begin{array}{l}6 \cdot 08(3 \cdot 71) \\
5 \cdot 04(3 \cdot 03) \\
8 \cdot 18(4 \cdot 71) \\
7 \cdot 59(4 \cdot 53)\end{array}$ & $\begin{array}{l}0.74(0.44) \\
0.78(0.40) \\
1.09(1.03) \\
1.28(0.81)\end{array}$ & $\begin{array}{l}42.9(61.9) \\
40.8(55.4) \\
31.9(53.1) \\
34.5(49.6)\end{array}$ & $\begin{array}{l}7 \cdot 1(4 \cdot 6) \\
4 \cdot 6(4 \cdot 0) \\
3 \cdot 3(4 \cdot 4) \\
4 \cdot 3(3 \cdot 9)\end{array}$ \\
\hline $\begin{array}{l}\text { Sensory conduction: } \\
\text { Median nerve } \\
\text { Ulnar nerve } \\
\text { Sural nerve }\end{array}$ & $\begin{array}{l}16(41) \\
14(34) \\
11(20)\end{array}$ & $\begin{array}{l}8(18) \\
5(15) \\
4(9)\end{array}$ & $\begin{array}{l}3.08(2.49) \\
2.79(2.27) \\
3.62(3.06)\end{array}$ & $\begin{array}{l}0.33(0.25) \\
0.25(0.25) \\
0.28(0.50)\end{array}$ & $\begin{array}{l}46 \cdot 0(57 \cdot 1) \\
43 \cdot 4(53 \cdot 4) \\
42 \cdot 5(50 \cdot 4)\end{array}$ & $\begin{array}{l}4.7(5.9) \\
3.9(5 \cdot 1) \\
3.7(4.2)\end{array}$ \\
\hline
\end{tabular}

CMAP = Compound muscle action potential; SAP = sensory action potential; $N C V=$ nerve conduction velocity.

^Sensory action potential could not be elicited at the median nerve in one, the ulnar nerve in one, and the sural nerve in five patients. 
worsening of the electrodiagnostic findings was not correlated with the delayed worsening of motor disturbance and was noticeable even when PNS manifestations improved.

\section{Discussion}

The description of the clinical course of polyneuropathy associated with hexacarbon intoxication is not consistent, probably because of differences in the source of the aetiological agent and the severity of clinical manifestations. Patients detected in a field survey ${ }^{7}$ may have a milder form of neuropathy, and therefore have less neurological dysfunction compared with those who visited a hospital. ${ }^{9}$ All the patients who participated in the present study had moderate or severe polyneuropathy.

The neurological manifestations and recovery course of peripheral nerve function in the present group were similar to those reported elsewhere. ${ }^{4-10}$ Recovery of sensory functions occurred earlier than motor functions, although sensory disturbance developed before muscle weakness. Postexposure progression of motor disturbance, which is a unique feature in hexacarbon intoxication, was observed in five patients. The reason why such a phenomenon did not occur in sensory disturbance is not known.

Tightness of the legs, indicating spasticity, was not uncommon (six of 11 patients). Lower extremity spasticity and hyperreflexia after partial recovery of PNS functions are frequently mentioned in hexacarbon induced neuropathy. ${ }^{238-10}$ These symptoms are considered good clinical evidence of CNS damage in chronic hexacarbon poisoning. ${ }^{2910}$ Diminution or disappearance of spasticity, however, as observed in the present patients, has not been reported. Reduction of muscle hypertonia in these patients may be related to increased natural peripheral stimulation and may be the sign of recovery of PNS function. ${ }^{14}$ The reversible nature of spasticity has probably been unrecognised in the past because of the short periods of follow up.

Muscle cramp, which followed closely the disappearance or diminution of spasticity, was an unpleasant symptom. Cramp like muscular pain was one of the major subjective symptoms among shoe industry workers with n-hexane induced neuropathy. ${ }^{8}$ In the Ohio outbreak of methyl n-butyl ketone intoxication Allen and colleagues also described mild cramping discomfort as one of the early sensory complaints of patients. ${ }^{3}$ Muscle cramps in the present group, which persisted until the end of the follow up, seemed different from those mentioned in previous reports. It is known that pathological muscle cramps can occur in motor unit hyperactivity, in some neuropathies, in a few muscle diseases, and with changes in composition of extracellular fluid. Considering the chronological sequence, the muscle cramps in these patients seemed not to be a sign of peripheral nerve involvement. Also, in view of the degeneration in the motor pathways in the lumbar spinal cord of hexacarbon intoxicated animals ${ }^{12}$ and the increased excitability of alpha motorneurons in patients with n-hexane induced polyneuropathy, ${ }^{15}$ it is postulated that muscle cramp is a sign of CNS damage in nhexane intoxication and results from denervational hyperactivity of alpha motorneurons in the spinal cord.

Abnormal colour vision, associated with mild pigment dystrophy and perifoveal capillary proliferation, has been reported among industrial workers exposed to $\mathrm{n}$-hexane vapour at concentrations of 423-1280 ppm for more than five years; these ophthalmological signs were regarded as a toxic effect of $n$-hexane. ${ }^{16}$ Two patients in the present study had mild dyschromatopsia at first examination (colour plate screening test) and the colour vision defect was still detectable four years later (100 hue test). Maculopathy in these patients was confirmed on funduscopic examination by an ophthalmologist. Impairment of colour vision seemed to be irreversible.

Delayed worsening of electrodiagnostic findings after exposure had ceased was first mentioned in the Ohio outbreak of methyl n-butyl ketone induced polyneuropathy. ${ }^{7}$ Cianchetti and colleagues also noted a delayed deterioration in motor nerve conduction velocity in toxic polyneuropathy among shoe industry workers. ${ }^{8}$ The delayed development of electrodiagnostic abnormalities was common in the present group. Detailed neurographic findings and studies of evoked potentials at follow up will be reported elsewhere.

This study indicates that patients with $\mathrm{n}$-hexane induced neuropathy have a good prognosis, even those confined to a wheelchair in the early stages. Spasticity emerging on recovery is functionally reversible, but muscle cramps and abnormal colour vision are probably permanent.

1 Spencer PS, Schaumburg HH. Ultrastructural studies of the dying-back process. IV. Differential vulnerability of PNS and CNS fibers in experimental central-peripheral distal axonopathies. J Neuropathol Exp Neurol 1977;36:300-20.

2 Schaumburg $\mathrm{HH}$, Spencer PS. Clinical and experimental studies of distal axonopathy - a frequent form of brain and nerve damage produced by environmental chemical hazards. Ann NY Acad Sci 1979;329:14-29.

3 Spencer PS, Couri D, Schaumburg HH. n-Hexane and methyl n-butyl ketone. In: Spencer PS, Schaumburg HH, eds. Experimental and clinical neurotoxicology. Baltimore: Williams \& Wilkins, 1980:456-75.

4 Jorgensen NK, Cohr KH. n-Hexane and its toxicological effects-a review. Scand J Work Environ Health 1981;7: 157-68.

5 Yamamura Y.n-Hexane polyneuropathy. Folia Psychiat Neurol Jap 1969;23:45-57.

6 Herskowitz A, Ishii N, Schaumburg HH. n-Hexane neuropathy. N Engl J Med 1971;285:82-5. 
7 Allen N, Mendell JR, Billmaier DJ, Fontaine RE, O'Neill J. Toxic polyneuropathy due to methyl n-butyl ketone. An industrial outbreak. Arch Neurol 1975;32:209-18.

8 Cianchetti C, Abbritti G, Perticoni G, Siracusa A, Curradi F. Toxic polyneuropathy of shoe-industry workers. A study of 122 cases. J Neurol Neurosurg Psychiatry 1976;39:1151-61.

9 Altenkirch $H$, Mager J, Stoltenburg G, Helmbrecht J. Toxic polyneuropathies after sniffing a glue thinner. $J$ Neurol 1977;214:137-52.

10 Korobkin R, Asbury AK, Summer AJ, Nielsen SI. Glue sniffing neuropathy. Arch Neurol 1975;32:158-62.

11 Wang JD, Chang YC, Kao KP, Huang CC, Lin CC, Yeh WY. An outbreak of $n$-hexane induced polyneuropathy among press proofing workers in Taipei. Am J Ind Med 1986;10: 111-8.

12 Chang YC, Yip PK. n-Hexane induced electroneurographic changes and early detection of n-hexane intoxication. Journal of the Formosan Medical Association 1987;86:194-200.

13 Chang YC. Neurotoxic effects of $n$-hexane on the human central nervous system: evoked potential abnormalities in n-hexane polyneuropathy. J Neurol Neurosurg Psychiatry 1987;50: 269-74.

14 Dimitrijevic MR. Spasticity. In: Swash M, Kennard C, eds Scientific basis of clinical neurology. Edinburgh: Churchill Livingstone, 1985:108-15.

15 Bravaccio F, Ammendola A, Barruffo L, Carlomagno S $\mathrm{H}$-reflex behaviour in glue ( $\mathrm{n}$-hexane) neuropathy. Clinical Toxicology 1981;18:1369-75.

16 Raitta C, Seppalainen AM, Huuskonen NS. n-Hexane maculopathy in industrial workers. Albrecht von Graefes Archiv für Klinische und Experimentelle Ophthalmologie 1978; 209:99-110.

Accepted 11 December 1989

\section{Destruction of manuscripts}

From 1 July 1985 articles submitted for publication will not be returned. Authors whose papers are rejected will be advised of the decision and the manuscripts will be kept under security for three months to deal with any inquiries and then destroyed. 